\section{BMJ Open \\ Respiratory \\ Research}

\title{
Combined pulmonary fibrosis and emphysema: effect of pulmonary rehabilitation in comparison with chronic obstructive pulmonary disease
}

\author{
Hiromi Tomioka, ${ }^{1}$ Nobuaki Mamesaya, ${ }^{1}$ Shyuji Yamashita, ${ }^{1}$ Yoko Kida, ${ }^{1}$ \\ Masahiro Kaneko, ${ }^{1}$ Hideki Sakai ${ }^{2}$
}

To cite: Tomioka $\mathrm{H}$, Mamesaya N, Yamashita S, et al. Combined pulmonary fibrosis and emphysema: effect of pulmonary rehabilitation in comparison with chronic obstructive pulmonary disease. BMJ Open Resp Res 2016;3: e000099. doi:10.1136/ bmjresp-2015-000099

Received 29 June 2015 Revised 5 October 2015 Accepted 23 November 2015

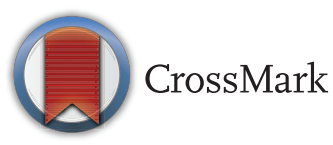

${ }^{1}$ Department of Respiratory Medicine, Kobe City Medical Center West Hospital, Kobe, Hyogo, Japan

${ }^{2}$ Department of Rehabilitation, Kobe City Medical Center West Hospital, Kobe, Hyogo, Japan

Correspondence to Dr Hiromi Tomioka; htomy@kobe-nishishiminhospi.jp

\section{ABSTRACT}

Objective: To evaluate the effectiveness of short-term comprehensive inpatient pulmonary rehabilitation for patients with combined pulmonary fibrosis and emphysema (CPFE), and to compare responses with those of patients with chronic obstructive pulmonary disease (COPD) who underwent an identical programme.

Design: Retrospective analysis of several outcome measures.

Setting: Pulmonary ward at a 358-bed community teaching hospital.

Methods: 3-week inpatient pulmonary rehabilitation programme assessed by pulmonary function tests, 6 min walk test and health-related quality of life (HRQL) using the Short Form-36 (SF-36).

Results: 17 patients with CPFE and 49 patients with COPD were referred to and completed the programme between March 2007 and February 2015. Age, sex, smoking status, body mass index and the Medical Research Council dyspnoea grade were comparable between groups. In the CPFE group, improvement from the start of the programme to the programme end was observed in forced expiratory volume in $1 \mathrm{~s}\left(\mathrm{FEV}_{1}\right)$ (from $1.7 \pm 0.4$ to $1.8 \pm 0.4, p=0.034$ ); however, there was no significant improvement in the 6 min walk test (distance, $\mathrm{SpO}_{2}$ nadir and Borg scale on exercise). With regard to HRQL, improvement was observed in physical function $(p=0.015)$ whereas deterioration was observed in social functioning ( $p=0.044)$. In the COPD group, significant improvement was observed after the programme in the $\mathrm{FEV}_{1}, 6$ min walk test and 4 of the 8 SF-36 subscales. There was a significant difference in changes in the 6 min walk distance: $-16.6 \pm 58.4$ in CPFE versus $30.2 \pm 55.6$ in COPD ( $p=0.009)$. In 2 domains, there was a significant difference in SF-36 scores between groups: $\Delta$ vitality, $-6.3 \pm 22.4$ in CPFE versus $11.3 \pm 21.1$ in COPD, $p=0.009$; and $\Delta$ social functioning, $-18.8 \pm 34.2$ in CPFE versus $5.3 \pm 35.9$ in COPD, $p=0.027$.

Conclusion: Patients with COPD derived greater benefits than those with CPFE, from the relatively short periods of inpatient pulmonary rehabilitation.

\section{KEY MESSAGES}

Patients with chronic obstructive pulmonary disease derived greater benefit from the inpatient pulmonary rehabilitation programme compared to patients with combined pulmonary fibrosis and emphysema (CPFE). Future research should focus on developing a pulmonary rehabilitation programme specifically tailored to the needs of patients with CPFE in an attempt to optimise the benefits of rehabilitation.

\section{INTRODUCTION}

Pulmonary rehabilitation is a comprehensive intervention based on thorough patient assessment followed by patient-tailored therapies, which include but are not limited to exercise training, education and behavioural changes, and are designed to improve the physical and psychological condition of people with chronic respiratory disease, and to promote long-term adherence to health-enhancing behaviours. ${ }^{1}$ Pulmonary rehabilitation is an integral part of the clinical management of patients with chronic respiratory disease. Most of the evidence supporting the effectiveness of pulmonary rehabilitation and development of guidelines comes from studies of patients with chronic obstructive pulmonary disease (COPD) for which pulmonary rehabilitation has been found to reduce dyspnoea, increase exercise capacity and improve quality of life. ${ }^{2}$

Emphysema is the main pathological feature of COPD, which is characterised by the permanent abnormal enlargement of airspaces distal to the terminal bronchioles, accompanied by destruction of their walls. The characteristics of emphysema do not, by definition, include thickening of the alveolar septa and fibrosis. The occurrence of both emphysema and pulmonary fibrosis in the same patient has received increased 
attention. The syndrome of combined pulmonary fibrosis and emphysema (CPFE) is a recently described entity associating upper-lobe emphysema with lower-lobe fibrosis. ${ }^{3}$ Given the evidence that pulmonary rehabilitation benefits a large population with COPD, it is a reasonable assumption that those with CPFE might benefit similarly. However, data on the effectiveness of pulmonary rehabilitation in patients with CPFE are scant. We therefore decided to elucidate the effectiveness of pulmonary rehabilitation in patients with CPFE in our cohort who participated in an inpatient pulmonary rehabilitation programme. The key question addressed in this study is whether pulmonary rehabilitation for patients with CPFE is as beneficial as it is for those with COPD.

\section{MATERIALS AND METHODS \\ Study participants}

Consecutive patients with CPFE and COPD without parenchymal lung disease with fibrosis who were referred to and completed the inpatient pulmonary rehabilitation programme at Kobe City Medical Center West Hospital, Kobe, Japan, between March 2007 and February 2015, were included in this study. Inclusion criteria were a stable clinical condition with no exacerbations in the preceding 2 weeks and written consent to participate in the programme. Patients with active cancer, unstable cardiac disease, or a history of neurological or orthopaedic disorders interfering with exercise, were excluded. CPFE was diagnosed when high-resolution CT (HRCT) chest scans showed emphysema occupying $>25 \%$ of both upper lobes ${ }^{4}$ and idiopathic diffuse parenchymal disease with fibrosis of the lower lung zones. ${ }^{5}$ COPD was diagnosed and its severity assessed in accordance with the Global Initiative for Chronic Obstructive Lung Disease (GOLD) 2014 guidelines. ${ }^{6}$ Patients with complicated parenchymal lung disease with fibrosis were excluded.

\section{Study design}

The study was a retrospective observational study of patients enrolled in our comprehensive pulmonary rehabilitation programme in a community hospital. Our institutional review board approved this retrospective study (reference number 15-001) and the requirement for informed consent was waived.

\section{Assessments}

Dyspnoea and functional status were evaluated using the Medical Research Council (MRC) dyspnoea grade (15). ${ }^{7}$ Cumulative cigarette consumption expressed as the smoking index was the number of cigarettes consumed per day multiplied by years of smoking. ${ }^{8}$ Pulmonary function tests were assessed using a spirometer (Autospirometer System 7, Minato, Tokyo, Japan) according to the method described in the American Thoracic Society 1994 update. $^{9}$ Predicted normal values for the Japanese population were derived from reference values of the Japanese Respiratory Society. ${ }^{10}$

We reviewed HRCT scans of the participants. HRCT scanning was performed by helical CT scanners (Optima CT 660, GE Healthcare, Tokyo, Japan or SOMATOM Sensation 64, SIEMENS, Tokyo, Japan) with 1.0 mm-thick axial sections taken at $1 \mathrm{~cm}$ intervals throughout the entire thorax and were reconstructed using a high-spatial frequency algorithm. Emphysema was scored visually in the upper, middle and lower fields of both lungs according to the methods of Goddard $e t a{ }^{4}{ }^{4}$ The score for each of the 6 lung fields was calculated according to the percentage of each lung field that was a lowattenuation area (\%LAA): score $0 \% \mathrm{LAA}<5 \%$; score 1 $\%$ LAA $5 \%$ to $<25 \%$; score $2 \%$ LAA $\geq 25 \%$ to $<50 \%$; score $3 \%$ LAA $\geq 50 \%$ to $<75 \%$; and score $4 \%$ LAA $\geq 75 \%$. Scores for each of the six lung fields were summed to obtain the total emphysema score. The HRCT images were analysed independently by a pulmonologist (HT) with no knowledge of the patients' clinical information.

Functional exercise capacity was measured by the 6 min walk test on a flat circuit, using the protocol proposed by Chang et al. ${ }^{11}$ Supplemental oxygen was permitted at the same concentration inspired normally during daily activities at baseline. Oxygen saturation was measured continuously during the walk, using a pulse oximeter. Only one $6 \mathrm{~min}$ walk test was performed. Patients were asked to rate their dyspnoea prior to and at the end of the test, using the Borg scale, ${ }^{12}$ by selecting a number from 0 to 10 , with 0 being no appreciable dyspnoea and 10 being maximal sustainable dyspnoea.

Health-related quality of life (HRQL) was assessed using the Short Form-36 (SF-36) Japanese test version, which is adapted and psychometrically validated for the Japanese population. ${ }^{13} 14$ The SF-36 is a widely used instrument that has been validated in various patient groups, including those with COPD, ${ }^{15}$ and has been shown to detect improvement after pulmonary rehabilitation. ${ }^{16}$ The questionnaire consists of 36 questions covering eight health concepts: physical function, role-physical, bodily pain, general health, vitality, social functioning, role-emotional and mental health. These eight health components were scored separately and transformed to a 0-100 scale according to the guidelines. ${ }^{17}$ An ascending scale was used for scoring, with higher scores indicating a better HRQL and lower scores, a worse quality of life. Methods for handling missed items were used according to those guidelines.

At entry, echocardiography was performed to detect pulmonary arterial hypertension. The pulmonary artery systolic pressure (PASP) was analysed in terms of tricuspid regurgitation peak velocity (TRPV) and right atrial pressure (RAP), using a colour Doppler technique $(\mathrm{PASP}=4 \times \mathrm{TRPV}+\mathrm{RAP}) .{ }^{18}$

Pulmonary function testing, 6 min walk test and SF-36 were administered at the beginning and end of the programme. All follow-up walk tests were conducted using 
the same flow rate of supplemental oxygen that had been used at baseline.

\section{Rehabilitation programme}

Participants attended a 3-week inpatient programme that included exercise training, breathing retraining and education. The exercise programme included stretches, peripheral muscle training on fitness equipment, stair climbing, bicycle training and inspiratory muscle training using Argyle Triball (Covidien Japan, Fukuroi, Japan). Argyle Triball training can provide sustained maximal inspiration training easily and effectively. Endurance training consisted of ground-based walking and cycling on an ergometer, mostly by interval training, guided by the Borg scale (score 5 for dyspnoea), ${ }^{19}$ or oxygen saturation $(>89 \%)$. Patients on long-term oxygen therapy or patients with significant arterial oxygen desaturation during exercise trained under administration of oxygen. Breathing retraining consisted of relaxation with breathing control, pursed-lip breathing and pacing during exercise training and activities of daily living. Rehabilitation sessions in the rehabilitation room consisted of $40 \mathrm{~min}$ of physiotherapy and $40 \mathrm{~min}$ of occupational therapy per day. The educational topics included those on medications and oxygen use, nutrition, panic control and methods of physical conditioning. Compliance with daily exercise was assessed every day using a training diary filled out by the patients. All other treatments, including those with medications and oxygen inhalation, remained unchanged during the pulmonary rehabilitation period. All patients received the same rehabilitation programme regardless of their underlying disease.

\section{Statistical analysis}

Measurement data were expressed as means \pm SD. Group differences were compared using the $\chi^{2}$ or Fisher's exact test for categorical variables, or the Student t test or the Mann-Whitney $\mathrm{U}$ test for continuous variables.

Within-group and between-group changes following rehabilitation were evaluated using paired $t$ tests, Wilcoxon signed-rank and Mann-Whitney $\mathrm{U}$ tests, respectively. Significance was defined as $p<0.05$. All analyses were performed using JMP statistical software (SAS Institute, Inc, Cary, North Carolina, USA).

\section{RESULTS}

\section{Clinical characteristics}

We studied 17 patients with CPFE and 49 patients with COPD. Of the 17 patients with CPFE, one patient had a possible normal interstitial pneumonia (UIP) pattern and the remaining 16 patients had the UIP pattern on chest HRCT in accordance with the 2011 Idiopathic Pulmonary Fibrosis (IPF) criteria. $^{20}$ The median duration from the detection of interstitial changes on CT to the initiation of pulmonary rehabilitation was 8.6 months (0-76.7 months) in the CPFE group. Three patients with CPFE were taking oral corticosteroids during the pulmonary rehabilitation period (daily prednisolone dose of 25,30 and $30 \mathrm{mg}$, respectively). The clinical characteristics of both groups are shown in table 1. Age, sex, smoking status, body mass index and MRC grade were comparable between the groups. Ten patients with CPFE and 26 patients with COPD were receiving home oxygen therapy. The median interval between the HRCT and the initiation of the pulmonary rehabilitation programme was 2.0 months $(0-$ 15.8 months) in the CPFE group and 1.5 months $(0$ 32.8 months) in the COPD group. The emphysema score was significantly higher in the COPD group compared with in the CPFE group $(\mathrm{p}<0.005)$.

There was no significant difference in forced vital capacity (FVC) between the groups; however, forced expiratory volume in $1 \mathrm{~s}\left(\mathrm{FEV}_{1}\right)$ and the $\mathrm{FEV}_{1} / \mathrm{FVC}$ were significantly smaller $(\mathrm{p}<0.0001)$ in the COPD group than in the CPFE group, reflecting the obstructive nature of the respiratory dysfunction in patients with COPD. Among patients with COPD, the numbers of patients with mild, moderate, severe and very severe COPD were 1, 4, 17 and 27, respectively. Patients with CPFE had a significantly higher PASP $(p=0.016)$. With regard to the $6 \mathrm{~min}$ walk test, there was no significant difference in distance and the $\mathrm{SpO}_{2}$ nadir between the two groups; however, the Borg scale for exercise was significantly higher in the COPD group. SF-36 scores were comparable between groups except for the vitality score, which was significantly lower in the COPD group than in the CPFE group.

\section{Effects of pulmonary rehabilitation in patients with CPFE}

Outcome measures prepulmonary and postpulmonary rehabilitation are described in table 2. Compared with preprogramme values, improvement was observed after pulmonary rehabilitation in $\mathrm{FEV}_{1}(\mathrm{p}=0.034)$; however, there was no significant improvement in the $6 \mathrm{~min}$ walk test (distance, $\mathrm{SpO}_{2}$ nadir and Borg scale on exercise). With regard to HRQL, improvement was observed in physical function $(p=0.015)$ whereas deterioration was observed in social functioning $(\mathrm{p}=0.044)$.

\section{Comparison of the effects of pulmonary rehabilitation between patients with CPFE and COPD}

In the COPD group, significant improvement was observed after pulmonary rehabilitation in $\mathrm{FEV}_{1}, 6 \mathrm{~min}$ walk test (distance, $\mathrm{SpO}_{2}$ nadir and Borg scale on exercise) and in four of the eight SF-36 subscales (physical function, general health, vitality and mental health; table 3).

Comparisons of changes in pulmonary function and the 6 min walk test between patients with CPFE and COPD are shown in table 4 . There was no significant difference in pulmonary function. On the other hand, there was a significant difference in changes in the 6 min walk distance: $-16.6 \pm 58.4$ in CPFE versus 30.2 \pm 55.6 in COPD ( $p=0.009$; figure 1$)$. The COPD group 
Table 1 Baseline characteristics of the study population

\begin{tabular}{|c|c|c|c|}
\hline & CPFE $(n=17)$ & COPD $(n=49)$ & p Value \\
\hline Age, years & $76.5 \pm 7.1$ & $73.4 \pm 9.0$ & 0.209 \\
\hline Males, n (\%) & $15(88.2)$ & $36(73.5)$ & 0.318 \\
\hline Smoking index & $989.7 \pm 574.1$ & $1304.2 \pm 745.4$ & 0.119 \\
\hline Former smokers, n (\%) & $16(94.1)$ & $41(83.7)$ & 0.428 \\
\hline Current smokers, n (\%) & $1(5.9)$ & $8(16.3)$ & \\
\hline Body mass index, $\mathrm{kg} / \mathrm{m}^{2}$ & $21.0 \pm 2.9$ & $20.0 \pm 4.0$ & 0.324 \\
\hline MRC grade $(1 / 2 / 3 / 4 / 5)$ & $0 / 0 / 8 / 8 / 1$ & 0/2/25/18/4 & 0.613 \\
\hline Home oxygen therapy, n (\%) & $10(58.8)$ & $26(53.1)$ & 0.898 \\
\hline Emphysema score & $9.1 \pm 3.2$ & $13.1 \pm 5.0$ & $<0.005$ \\
\hline \multicolumn{4}{|l|}{ Pulmonary function } \\
\hline FVC, litres & $2.1 \pm 0.5$ & $1.8 \pm 0.7$ & 0.136 \\
\hline FVC, \%predicted & $67.2 \pm 15.9$ & $59.3 \pm 18.7$ & 0.124 \\
\hline $\mathrm{FEV}_{1}$, litres & $1.7 \pm 0.4$ & $0.8 \pm 0.5$ & $<0.0001$ \\
\hline $\mathrm{FEV}_{1}, \%$ predicted & $70.6 \pm 14.2$ & $33.8 \pm 16.6$ & $<0.0001$ \\
\hline $\mathrm{FEV}_{1} / \mathrm{FVC}, \%$ & $82.8 \pm 10.1$ & $44.4 \pm 13.9$ & $<0.0001$ \\
\hline PASP, mm Hg & $54.2 \pm 26.1$ & $42.7 \pm 10.2(n=45)$ & 0.016 \\
\hline 6 min walk test & $\mathrm{n}=15$ & $\mathrm{n}=44$ & \\
\hline Distance, m & $270.5 \pm 59.4$ & $216.0 \pm 99.1$ & 0.054 \\
\hline $\mathrm{SpO}_{2}$ nadir, \% & $85.1 \pm 8.6$ & $87.8 \pm 6.5$ & 0.221 \\
\hline Borg scale & $3.9 \pm 1.5$ & $5.2 \pm 2.1$ & 0.035 \\
\hline Short Form-36 & $n=16$ & $n=45$ & \\
\hline Physical function & $38.3 \pm 23.7$ & $31.9 \pm 19.6$ & 0.299 \\
\hline Role-physical & $36.8 \pm 27.9$ & $31.1 \pm 25.2$ & 0.451 \\
\hline Body pain & $60.1 \pm 29.0$ & $51.4 \pm 26.9$ & 0.280 \\
\hline General health & $40.4 \pm 18.1$ & $32.6 \pm 18.3$ & 0.143 \\
\hline Vitality & $42.2 \pm 24.8$ & $29.3 \pm 19.8$ & 0.041 \\
\hline Social functioning & $57.8 \pm 33.8$ & $56.1 \pm 30.3$ & 0.852 \\
\hline Role-emotional & $37.0 \pm 27.0$ & $31.7 \pm 28.7$ & 0.521 \\
\hline Mental health & $56.3 \pm 19.4$ & $43.6 \pm 22.8$ & 0.053 \\
\hline
\end{tabular}

COPD, chronic obstructive pulmonary disease; CPFE, combined pulmonary fibrosis and emphysema; FEV ${ }_{1}$, forced expiratory volume in $1 \mathrm{~s}$; FVC, forced vital capacity; MRC, Medical Research Council; PASP, pulmonary artery systolic pressure.

Table 2 Effects of pulmonary rehabilitation in patients with combined pulmonary fibrosis and emphysema

\begin{tabular}{lccc}
\hline \multicolumn{1}{c}{ Pre-PR } & Post-PR & p Value \\
\hline Pulmonary function $(\mathrm{n}=17)$ & & \\
FVC, litres & $2.1 \pm 0.5$ & $2.1 \pm 0.6$ & 0.276 \\
FEV ${ }_{1}$, litres & $1.7 \pm 0.4$ & $1.8 \pm 0.4$ & 0.034 \\
6 min walk test $(\mathrm{n}=15)$ & & & \\
Distance, m & $270.5 \pm 59.4$ & $253.9 \pm 71.3$ & 0.290 \\
SpO $_{2}$ nadir, \% & $85.1 \pm 8.6$ & $86.9 \pm 7.7$ & 0.467 \\
Borg scale & $3.9 \pm 1.5$ & $3.1 \pm 1.9$ & 0.089 \\
Short Form-36 $(\mathrm{n}=16)$ & & & \\
Physical function & $38.3 \pm 23.7$ & $54.3 \pm 27.6$ & 0.015 \\
Role-physical & $36.8 \pm 27.9$ & $31.0 \pm 31.7$ & 0.479 \\
Body pain & $60.1 \pm 29.0$ & $55.8 \pm 34.0$ & 0.563 \\
General health & $40.4 \pm 18.1$ & $37.6 \pm 16.6$ & 0.562 \\
Vitality & $42.2 \pm 24.8$ & $35.9 \pm 21.2$ & 0.281 \\
Social functioning & $57.8 \pm 33.8$ & $39.1 \pm 32.9$ & 0.044 \\
Role-emotional & $37.0 \pm 27.0$ & $31.3 \pm 32.8$ & 0.273 \\
Mental health & $56.3 \pm 19.4$ & $53.1 \pm 23.9$ & 0.539 \\
\hline
\end{tabular}

FEV ${ }_{1}$, forced expiratory volume in $1 \mathrm{~s}$; FVC, forced vital capacity; $\mathrm{PR}$, pulmonary rehabilitation.
Table 3 Effects of pulmonary rehabilitation in patients with chronic obstructive pulmonary disease

\begin{tabular}{|c|c|c|c|}
\hline & Pre-PR & Post-PR & p Value \\
\hline \multicolumn{4}{|c|}{ Pulmonary function $(n=42)$} \\
\hline FVC, litres & $1.9 \pm 0.7$ & $1.8 \pm 0.8$ & 0.933 \\
\hline $\mathrm{FEV}_{1}$, litres & $0.8 \pm 0.5$ & $0.9 \pm 0.5$ & 0.042 \\
\hline \multicolumn{4}{|l|}{6 min walk test $(n=37)$} \\
\hline Distance, $\mathrm{m}$ & $223.6 \pm 102.4$ & $253.9 \pm 94.2$ & 0.002 \\
\hline $\mathrm{SpO}_{2}$ nadir, \% & $87.4 \pm 6.9$ & $89.4 \pm 5.8$ & 0.024 \\
\hline Borg scale & $5.2 \pm 1.9$ & $3.8 \pm 2.4$ & 0.002 \\
\hline \multicolumn{4}{|l|}{ Short Form-36 $(n=38)$} \\
\hline Physical function & $29.7 \pm 18.0$ & $38.8 \pm 22.1$ & 0.001 \\
\hline Role-physical & $32.4 \pm 26.1$ & $38.9 \pm 26.7$ & 0.304 \\
\hline Body pain & $52.4 \pm 28.7$ & $51.2 \pm 27.6$ & 0.824 \\
\hline General health & $30.6 \pm 17.2$ & $36.9 \pm 23.1$ & 0.023 \\
\hline Vitality & $26.7 \pm 18.1$ & $38.0 \pm 20.3$ & 0.002 \\
\hline Social functioning & $54.9 \pm 31.8$ & $60.2 \pm 28.2$ & 0.372 \\
\hline Role-emotional & $32.5 \pm 30.1$ & $43.9 \pm 27.2$ & 0.069 \\
\hline Mental health & $42.7 \pm 24.1$ & $50.8 \pm 21.9$ & 0.034 \\
\hline
\end{tabular}

$\mathrm{FEV}_{1}$, forced expiratory volume in $1 \mathrm{~s}$; FVC, forced vital capacity; $\mathrm{PR}$, pulmonary rehabilitation. 
Table 4 Comparison of changes in pulmonary function and 6 min walk test between patients with CPFE, and those with COPD

\begin{tabular}{|c|c|c|c|}
\hline & CPFE & COPD & p Value \\
\hline Pulmonary function & $\mathrm{n}=17$ & $\mathrm{n}=42$ & \\
\hline$\Delta \mathrm{FVC}$, litres & $0.08 \pm 0.30$ & $-0.004 \pm 0.34$ & 0.366 \\
\hline$\Delta \mathrm{FEV}_{1}$, litres & $0.10 \pm 0.18$ & $0.04 \pm 0.13$ & 0.151 \\
\hline 6 min walk test & $n=15$ & $\mathrm{n}=37$ & \\
\hline$\Delta$ Distance, $\mathrm{m}$ & $-16.6 \pm 58.4$ & $30.2 \pm 55.6$ & 0.009 \\
\hline$\Delta \mathrm{SpO}_{2}$ nadir, $\%$ & $1.6 \pm 8.2$ & $2.0 \pm 5.1$ & 0.863 \\
\hline$\Delta$ Borg scale & $-0.9 \pm 1.8$ & $-1.4 \pm 2.5$ & 0.453 \\
\hline
\end{tabular}

had a mean improvement of $>25 \mathrm{~m}$, the distance that has been suggested as the minimum change for a clinical improvement ${ }^{21}$ in COPD. There was no significant difference in changes in the $\mathrm{SpO}_{2}$ nadir and Borg scale on exercise. Mean changes in SF-36 subscales from baseline values for CPFE and COPD are shown in figure 2. There was a tendency toward improvement in all domains of the SF-36 with the exception of bodily pain in the COPD group; however, there was a tendency toward deterioration in all domains with the exception of physical function in the CPFE group. Statistically significant differences in changes in vitality $(\mathrm{p}=0.009)$ and social functioning $(\mathrm{p}=0.027)$ were found between CPFE and COPD.

\section{Subgroup analysis of patients with CPFE according to results of the 6 min walk tests}

We performed subgroup analysis of patients with CPFE for whom both baseline and follow-up 6 min walk test data were available. Baseline clinical characteristics were compared between participants whose 6 min walk distance decreased after pulmonary rehabilitation
CPFE

COPD

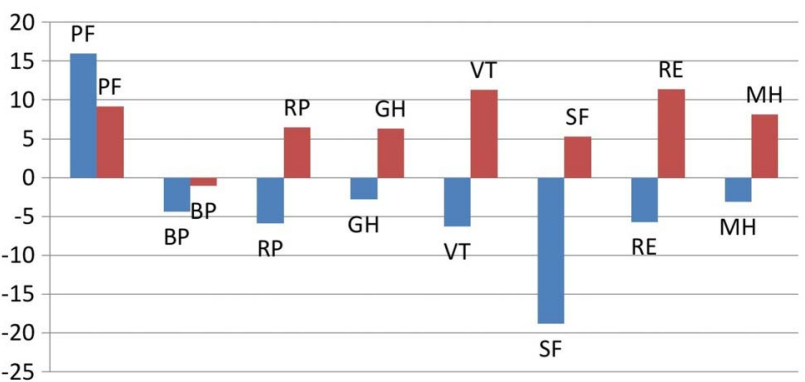

Figure 2 Mean changes in the Short Form-36 subscales from baseline values for combined pulmonary fibrosis and emphysema (CPFE) $(n=16)$, and chronic obstructive pulmonary disease (COPD) $(n=38)$. Statistically significant differences in changes in vitality $(\mathrm{p}=0.009)$ and social functioning $(p=0.027)$ were found between CPFE and COPD. $\mathrm{PF}$, physical function; RP, role-physical; BP, bodily pain; $\mathrm{GH}$, general health; VT, vitality; SF, social functioning; RE, role-emotional; $\mathrm{MH}$, mental health.

(worsening of 6 min walk test) and participants whose 6 min walk distance did not (stable or improved 6 min walk test; table 5). Although the study included only a small number of patients with CPFE, patients with CPFE with worsening of the 6 min walk test had a tendency to have a higher PASP $(p=0.075)$ than those with stable or improved 6 min walk test results. Also, the percentage of patients who had PASP $>40 \mathrm{~mm} \mathrm{Hg}$ was significantly greater in the former group $(80.0 \%)$ than in the latter group $(20.0 \%)(p=0.023)$. The baseline Borg scale on exercise was significantly higher in the group with worsening 6 min walk test results compared with those with improved scores $(\mathrm{p}=0.031)$.

\section{DISCUSSION}

The present study showed that, in patients with CPFE, there was no significant improvement in exercise
Figure 1 Changes in 6 min walk distance (6MWD) for combined pulmonary fibrosis and emphysema (CPFE) $(n=15)$, and chronic obstructive pulmonary disease (COPD) $(n=37)$. There was a significant difference in changes in the 6 min walk distance; $-16.6 \pm 58.4$ in CPFE vs $30.2 \pm 55.6$ in COPD ( $p=0.009)$. $\mathrm{PR}$, pulmonary rehabilitation.

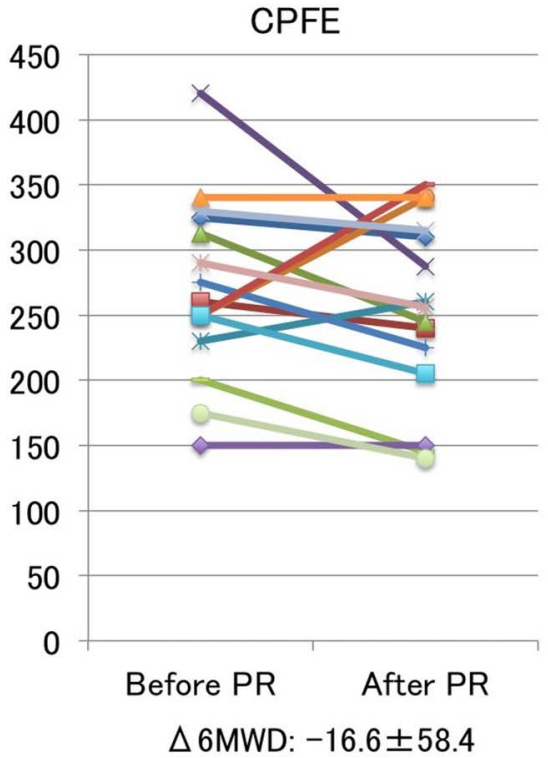


Table 5 Comparison of baseline characteristics between patients with combined pulmonary fibrosis and emphysema (CPFE) whose 6 min walk distance decreased (worsening of 6 min walk test (6MWT)) and participants whose 6 min walk distance did not decrease (stable or improved 6MWT)

\begin{tabular}{|c|c|c|c|}
\hline & Worsening of 6MWT $(n=10)$ & Stable or improved 6MWT $(n=5)$ & p Value \\
\hline Age, years & $76.2 \pm 8.7$ & $75.8 \pm 5.0$ & 0.927 \\
\hline Male, n (\%) & $8(80.0)$ & $5(100)$ & 0.524 \\
\hline Smoking index & $1147.5 \pm 672.1$ & $830.0 \pm 363.3$ & 0.347 \\
\hline Time since diagnosis, months & $52.1 \pm 41.7$ & $18.2 \pm 16.2$ & 0.141 \\
\hline Body mass index, $\mathrm{kg} / \mathrm{m}^{2}$ & $22.1 \pm 3.0$ & $20.3 \pm 1.5$ & 0.233 \\
\hline MRC grade $(1 / 2 / 3 / 4 / 5)$ & $0 / 0 / 5 / 5 / 0$ & $0 / 0 / 3 / 2 / 0$ & 0.573 \\
\hline Corticosteroid therapy, n (\%) & $1(10.0)$ & $2(40.0)$ & 0.242 \\
\hline Home oxygen therapy, n (\%) & $6(60.0)$ & $2(40.0)$ & 0.401 \\
\hline Emphysema score & $10.0 \pm 3.5$ & $7.6 \pm 2.3$ & 0.191 \\
\hline \multicolumn{4}{|l|}{ Pulmonary function } \\
\hline FVC, litres & $2.1 \pm 0.6$ & $2.0 \pm 0.4$ & 0.616 \\
\hline FVC, \%pred & $70.6 \pm 16.0$ & $62.1 \pm 8.4$ & 0.291 \\
\hline $\mathrm{FEV}_{1}$, litres & $1.7 \pm 0.4$ & $1.6 \pm 0.5$ & 0.680 \\
\hline $\mathrm{FEV}_{1}, \%$ predicted & $74.2 \pm 12.0$ & $64.2 \pm 14.1$ & 0.174 \\
\hline $\mathrm{FEV}_{1} / \mathrm{FVC}, \%$ & $83.0 \pm 10.9$ & $81.4 \pm 10.0$ & 0.788 \\
\hline PASP, mm Hg & $53.2 \pm 12.5$ & $39.0 \pm 10.7$ & 0.075 \\
\hline PASP >40 mm Hg, $\mathrm{n}(\%)$ & $8(80.0 \%)$ & $1(20.0 \%)$ & 0.023 \\
\hline \multicolumn{4}{|l|}{ Baseline 6 min walk test } \\
\hline Distance, m & $283.8 \pm 69.8$ & $244.0 \pm 67.7$ & 0.313 \\
\hline $\mathrm{SpO}_{2}$ nadir, \% & $82.8 \pm 9.3$ & $89.8 \pm 4.3$ & 0.140 \\
\hline Borg scale & $4.5 \pm 1.4$ & $2.8 \pm 1.1$ & 0.031 \\
\hline \multicolumn{4}{|l|}{ Short Form-36 } \\
\hline Physical function & $39.8 \pm 20.1$ & $43.0 \pm 28.4$ & 0.800 \\
\hline Role-physical & $34.4 \pm 20.5$ & $47.9 \pm 39.6$ & 0.391 \\
\hline Body pain & $58.3 \pm 28.0$ & $67.6 \pm 34.9$ & 0.585 \\
\hline General health & $37.7 \pm 19.6$ & $40.0 \pm 11.2$ & 0.813 \\
\hline Vitality & $40.0 \pm 23.0$ & $37.5 \pm 23.8$ & 0.848 \\
\hline Social functioning & $57.5 \pm 34.0$ & $57.5 \pm 41.1$ & 1.000 \\
\hline Role-emotional & $39.2 \pm 26.1$ & $35.0 \pm 34.1$ & 0.796 \\
\hline Mental health & $61.5 \pm 18.6$ & $45.0 \pm 20.0$ & 0.138 \\
\hline
\end{tabular}

tolerance and exertional dyspnoea after 3 weeks of comprehensive inpatient pulmonary rehabilitation. With regard to HRQL, significant improvement was observed in only physical function whereas significant deterioration was observed in social functioning. In contrast, age-matched and MRC grade-matched COPD participants benefited from the same programme with improvements in exercise tolerance, exertional dyspnoea and HRQL. There was a significant difference in changes in the 6 min walk distance between those with CPFE and those with COPD. Data examining the role of pulmonary rehabilitation in chronic lung diseases other than COPD are limited. To the best of our knowledge, this is the first study to elucidate the effects of pulmonary rehabilitation in patients with CPFE.

We should consider the reason for the lack of favourable effects of pulmonary rehabilitation in our patients with CPFE. First, our pulmonary rehabilitation programme was in an inpatient setting over a relatively short period. According to the GOLD statement, ${ }^{6}$ the duration of an effective pulmonary rehabilitation programme is 6 weeks, and the longer the programme continues, the more effective the results. Therefore, our 3-week programme may be too short to show benefits. In addition, although there have been numerous studies involving pulmonary rehabilitation, few have concentrated on the outcome of inpatient programmes. Votto et $a l^{22}$ reported significant short-term improvement in exercise tolerance, dyspnoea and HRQL following inpatient programmes as short as 10 days in patients with severe COPD. Stewart $e t a l^{23}$ examined the effect of an inpatient programme with an average stay of 21 days, which was similar to our programme. They showed improved endurance and functional ambulation, decreased supplemental oxygen use and fewer hospitalisations 1 year after discharge for patients with moderate-to-severe COPD. Katsura $e t a l^{24}$ also reported long-term effectiveness of a 2-week inpatient programme for elderly patients with COPD. These data suggest that relatively short periods of inpatient pulmonary rehabilitation can result in beneficial outcome measures in patients with COPD. A shorter programme has the potential to reduce the cost per patient served and to spread limited resources. ${ }^{25}$ Therefore, we provided a 3-week pulmonary rehabilitation programme in an inpatient setting in consideration of the Japanese 
healthcare system, transportation to and from the programme, and patient-specific factors such as disease severity and the degree of disability. ${ }^{1}$ As mentioned above, patients with COPD benefited from our programme. In particular, the change in the 6 min walk distance was $>25 \mathrm{~m}$, which is considered to be clinically significant. ${ }^{21}$ We believe that our pulmonary rehabilitation programme is effective for patients with COPD even in an inpatient setting over a relatively short period. Although a floor effect may be present, because of the lower baseline for the 6 min walk distance in the COPD group compared to the CPFE group, a longer duration for evaluating the effects of pulmonary rehabilitation in an outpatient setting is needed, more in the CPFE group than in the COPD group.

Second, our exercise training regimens might not be appropriate for patients with CPFE. Although the syndrome of CPFE includes emphysema, it is also recognised as an interstitial lung disease (ILD). Common manifestations of ILD include exertional dyspnoea, hypoxaemia that often worsens with activity or exercise, fatigue, deconditioning and diminished HRQL. ${ }^{11}$ 26-29 Data examining the role of pulmonary rehabilitation in ILD are limited and optimal strategies for exercise training for patients with ILD have not been established. ${ }^{30}$ Exercise training regimens for these patients have been based on protocols shown to be effective in patients with COPD. Most dyspnoea control techniques have been developed to address the dynamic hyperinflation associated with COPD. It remains unclear if these techniques are effective for CPFE. It was suggested that dynamic hyperinflation is not associated with the impairment of pulmonary function in patients with CPFE without airflow obstruction. ${ }^{31}$ In addition, although both low-intensity and high-intensity exercise training produce clinical benefits for patients with COPD ${ }^{32}$ training at a relatively high intensity $(>60 \%$ maximal work rate) may be needed to achieve a physiological training benefit. ${ }^{33}{ }^{34}$ However, Kozu et $a l^{35}$ reported that patients with IPF, a specific form of chronic fibrosing ILD, were unable to increase the intensity of exercise as rapidly as the patients with COPD, due to dyspnoea and/or cough and profound desaturation.

Exercise intolerance is a key feature of ILD and is often associated with marked dyspnoea on exertion. ${ }^{1}$ The mechanisms of the respiratory limitations in COPD and ILD differ. Impaired pulmonary gas exchange 263637 and circulatory factors ${ }^{38}$ may be the major limitations to exercise in ILD. On the other hand, ventilatory limitations and skeletal muscle dysfunction, which are the predominant factors contributing to exercise limitations in COPD,${ }^{39}$ are present in COPD and ILD. ${ }^{35}{ }^{40}$ The similarities in clinical problems (exercise intolerance, muscle dysfunction, dyspnoea, impaired quality of life) suggest that pulmonary rehabilitation may also benefit patients with ILD. ${ }^{130}$ Emerging evidence has suggested that pulmonary rehabilitation might result in meaningful benefits for patients with ILD. ${ }^{41-46}$ However, the magnitude of these benefits has been noted to be smaller than that generally seen in COPD, ${ }^{35} 47$ and no ongoing effects were evident 6 months after training. ${ }^{42}$ Naji et $a l^{11}$ reported a relatively large dropout number, suggesting that a standard COPD programme may not be ideal for patients with restrictive lung disease, including ILD. Kozu et $a l^{35}$ reported no changes in SF-36 scores in the IPF group after 8-week outpatient pulmonary rehabilitation. They also suggested that pulmonary rehabilitation might have a reduced clinical benefit for patients with IPF classified as MRC grade $3-5 .{ }^{47}$ On the other hand, it was reported that pulmonary rehabilitation was successful for COPD irrespective of the MRC dyspnoea grade. ${ }^{48}$ All of our patients with CPFE were classified as MRC grade 3-5. Therefore, pulmonary rehabilitation might have a reduced clinical benefit for our CPFE population.

Some clinical characteristics differ between patients with CPFE and patients with COPD. Kitaguchi et at $t^{49}$ described the clinical characteristics of patients with CPFE and compared them with clinical characteristics of COPD. They reported that CPFE was characterised by subnormal spirometry (mild airflow limitation and mild lung hyperinflation), severe impairment of gas exchange and desaturation during exercise. In our study, we found that patients with CPFE had significantly higher PASP determined by echocardiography. Pulmonary hypertension was often observed in patients with CPFE, ${ }^{3}$ 50-52 and was associated with dyspnoea during exercise and/ or decreased exercise tolerance in patients with CPFE. ${ }^{51}$ The cardiovascular system is affected by chronic respiratory disease in a number of ways, the most important being an increase in right ventricular afterload. As COPD and pulmonary fibrosis are common causes of pulmonary hypertension, CPFE may strongly influence the development and progression of pulmonary hypertension by an additive or synergistic effect. ${ }^{52}$ Therefore, a higher frequency of pulmonary hypertension and greater severity may explain why our pulmonary rehabilitation programme lacked effectiveness in our CPFE population. In fact, our subgroup analysis of patients with CPFE showed that pulmonary hypertension as evaluated by echocardiography might be related to changes in the $6 \mathrm{~min}$ walk distance after pulmonary rehabilitation. Historically, recommendation has been to limit exercise in patients with pulmonary hypertension. Although the optimal exercise training programme for patients with pulmonary hypertension remains currently unknown, exercise should begin with brief sessions at low intensity with careful, incrementally progressive submaximal levels. ${ }^{1}{ }^{53}$ Furthermore, on the basis of observed haemodynamic responses to exercise in this patient population, it would be prudent to avoid interval training because of the associated rapid changes in pulmonary haemodynamics and risk of syncope. ${ }^{153}$

The present study has several limitations. First, it was a retrospective study at a single centre. Therefore, some selection bias may have affected our findings, and the results of some physiological tests and the HRQL were 
not available. In addition, there was a considerable interval between the performance of CT and the completion of the rehabilitation programme. Second, the study was based on a small number of patients. A larger study will be needed to confirm the results. Third, although our study concentrated on the short-term outcome of the inpatient programme, the long-term effectiveness of the programme also should be examined.

In conclusion, patients with COPD derived greater benefit from the inpatient pulmonary rehabilitation programme compared to patients with CPFE. Future research should focus on developing a pulmonary rehabilitation programme specifically tailored to the needs of patients with CPFE in an attempt to optimise the benefits of rehabilitation.

\section{Competing interests None declared.}

Provenance and peer review Not commissioned; externally peer reviewed.

\section{Data sharing statement No additional data are available.}

Open Access This is an Open Access article distributed in accordance with the Creative Commons Attribution Non Commercial (CC BY-NC 4.0) license, which permits others to distribute, remix, adapt, build upon this work noncommercially, and license their derivative works on different terms, provided the original work is properly cited and the use is non-commercial. See: http:// creativecommons.org/licenses/by-nc/4.0/

\section{REFERENCES}

1. Maltais F, Decramer M, Casaburi R, et al, ATS/ERS Ad Hoc Committee on Limb Muscle Dysfunction in COPD. An official American Thoracic Society/European Respiratory Society statement: update on limb muscle dysfunction in chronic obstructive pulmonary disease. Am J Respir Crit Care Med 2014;189:e15-62.

2. Nici L, Donner C, Wouters E, et al, ATS/ERS Pulmonary Rehabilitation Writing Committee. American Thoracic Society/ European Respiratory Society statement on pulmonary rehabilitation Am J Respir Crit Care Med 2006;173:1390-413.

3. Cottin V, Nunes H, Brillet PY, et al, Groupe d'Etude et de Recherche sur les Maladies Orphelines Pulmonaires (GERM O P). Combined pulmonary fibrosis and emphysema: a distinct underrecognised entity. Eur Respir J 2005;26:586-93.

4. Goddard PR, Nicholson EM, Laszlo G, et al. Computed tomography in pulmonary emphysema. Clin Radiol 1982;33:379-87.

5. Gotway MB, Freemer MM, King TE Jr. Challenges in pulmonary fibrosis. 1: use of high resolution CT scanning of the lung for the evaluation of patients with idiopathic interstitial pneumonias. Thorax 2007;62:546-53.

6. GOLD. The global strategy for the diagnosis, management, and prevention of COPD. Global Initiative for Chronic Obstructive Lung Disease (GOLD), 2014. http://www.goldcopd.org/ (accessed 4 Jun 2014)

7. Fletcher CM, Elmes PC, Fairbairn AS, et al. The significance of respiratory symptoms and the diagnosis of chronic bronchitis in a working population. BMJ 1959;2:257-66.

8. Brinkman GL, Coates EO Jr. The effect of bronchitis, smoking and occupation on ventilation. Am Rev Respir Dis 1963:87:684-93.

9. Medical Section of the American Lung Association. Standardization of spirometry: 1994 update. Am J Respir Crit Care Med 1995:152:1107-36.

10. The Japanese Respiratory Society. Special Committee of Pulmonary Physiology. Standard values of spirogram and arterial blood gas in normal Japanese subjects. Nihon Kokyuki Gakkai Zashi 2001;39: s1-17 (in Japanese)

11. Chang JA, Curtis JR, Patrick DL, et al. Assessment of healthrelated quality of life in patients with interstitial lung disease. Chest 1999;116:1175-82.

12. Borg GA. Psychophysical bases of perceived exertion. Med Sci Sports Exerc 1982:14:377-81.

13. Fukuhara S, Ware JE, Kosinski M, et al. Psychometric and clinical tests of validity of the Japanese SF-36 health survey. J Clin Epidemiol 1998;51:1045-53.
14. Fukuhara S, Bito S, Green J, et al. Translation, adaptation, and validation of the SF-36 health survey for use in Japan. $J$ Clin Epidemiol 1998;51:1037-44.

15. Mahler DA, Mackowiak Jl. Evaluation of the short-form 36-item questionnaire to measure health-related quality of life in patients with COPD. Chest 1995;107:1585-9.

16. Boueri FM, Bucher-Bartelson BL, Glenn KA, et al. Quality of life measured with a generic instrument (Short Form-36) improves following pulmonary rehabilitation in patients with COPD. Chest 2001;119:77-84.

17. Fukuhara S, Suzukamo Y, Bito S, et al. Manual of SF-36 Japanese version 1.2. Tokyo: Public Health Research Foundation, 2001:59-79 (in Japanese).

18. Kitabatake A, Inoue M, Asao M, et al. Noninvasive evaluation of pulmonary hypertension by a pulsed Doppler technique. Circulation 1983;68:302-9.

19. Mejia R, Ward J, Lentine $\mathrm{T}$, et al. Target dyspnea ratings predict expected oxygen consumption as well as target heart rate values. Am J Respir Crit Care Med 1999;159:1485-9.

20. Raghu G, Collard HR, Egan JJ, et al, ATS/ERS/JRS/ALAT Committee on Idiopathic Pulmonary Fibrosis. An official ATS/ERS/ JRS/ALAT statement: idiopathic pulmonary fibrosis: evidence based guidelines for diagnosis and management. Am J Respir Crit Care Med 2011;183:788-824.

21. Holland AE, Hill CJ, Rasekaba T, et al. Updating the minimal important difference for six-minute walk distance in patients with chronic obstructive pulmonary disease. Arch Phys Med Rehabil 2010;91:221-5

22. Votto J, Bowen J, Scalise P, et al. Short-stay comprehensive inpatient pulmonary rehabilitation for advanced chronic obstructive pulmonary disease. Arch Phys Med Rehabil 1996;77:1115-18.

23. Stewart DG, Drake DF, Robertson C, et al. Benefits of an inpatient pulmonary rehabilitation program: a prospective analysis. Arch Phys Med Rehabil 2001;82:347-52.

24. Katsura $\mathrm{H}$, Kanemaru $\mathrm{A}$, Yamada $\mathrm{K}$, et al. Long-term effectiveness of an inpatient pulmonary rehabilitation program for elderly COPD patients: comparison between young-elderly and old-elderly groups. Respirology 2004:9:230-6.

25. Clini E, Foglio K, Bianchi L, et al. In-hospital short-term training program for patients with chronic airway obstruction. Chest 2001;120:1500-5.

26. Markovitz GH, Cooper CB. Exercise and interstitial lung disease. Curr Opin Pulm Med 1998:4:272-80.

27. Swigris JJ, Gould MK, Wilson SR. Health-related quality of life among patients with idiopathic pulmonary fibrosis. Chest 2005:127:284-94

28. Nishiyama $\mathrm{O}$, Taniguchi $\mathrm{H}$, Kondoh $\mathrm{Y}$, et al. Health-related quality of life in patients with idiopathic pulmonary fibrosis. What is the main contributing factor? Respir Med 2005:99:408-14.

29. Tomioka H, Imanaka K, Hashimoto K, et al. Health-related quality of life in patients with idiopathic pulmonary fibrosis-cross-sectional and longitudinal study. Intern Med 2007;46:1533-42.

30. Swigris JJ, Brown KK, Make BJ, et al. Pulmonary rehabilitation in idiopathic pulmonary fibrosis: a call for continued investigation. Respir Med 2008;102:1675-80.

31. Kitaguchi Y, Fujimoto K, Hanaoka M, et al. Pulmonary function impairment in patients with combined pulmonary fibrosis and emphysema with and without airflow obstruction. Int J Chron Obstruct Pulmon Dis 2014:9:805-11.

32. Ries AL, Bauldoff GS, Carlin BW, et al. Pulmonary rehabilitation: Joint ACCP/AACVPR Evidence-Based Clinical Practice Guidelines. Chest 2007;131:4S-42S.

33. Casaburi R, Patessio A, loli F, et al. Reductions in exercise lactic acidosis and ventilation as a result of exercise training in patients with obstructive lung disease. Am Rev Respir Dis 1991;143:9-18.

34. Eves ND, Sandmeyer LC, Wong EY, et al. Helium-hyperoxia: a novel intervention to improve the benefits of pulmonary rehabilitation for patients with COPD. Chest 2009:135:609-18.

35. Kozu R, Senjyu H, Jenkins SC, et al. Differences in response to pulmonary rehabilitation in idiopathic pulmonary fibrosis and chronic obstructive disease. Respiration 2011;81:196-205.

36. Agusti AG, Roca J, Gea J, et al. Mechanisms of gas exchange impairment in idiopathic pulmonary fibrosis. Am Rev Respir Dis 1991;143:219-25.

37. Harris-Eze AO, Sridhar G, Clemens RE, et al. Role of hypoxemia and pulmonary mechanics in exercise limitation in interstitial lung disease. Am J Respir Crit Care Med 1996;154:994-1001.

38. Hansen JE, Wasserman K. Pathophysiology of activity limitation in patients with interstitial lung disease. Chest 1996;109:1566-76.

39. Pepin V, Saey D, Laviolette L, et al. Exercise capacity in chronic obstructive pulmonary disease: mechanisms of limitation. COPD 2007;4:195-204. 
40. Nishyiama $\mathrm{O}$, Taniguchi $\mathrm{H}$, Kondoh $\mathrm{Y}$, et al. Quadriceps weakness is related to exercise capacity in idiopathic pulmonary fibrosis. Chest 2005;127:2028-33.

41. Naji NA, Connor MC, Donnelly SC, et al. Effectiveness of pulmonary rehabilitation in restrictive lung disease. J Cardiopulm Rehabil 2006;26:237-43.

42. Holland $\mathrm{AE}$, Hill CJ, Conron $\mathrm{M}$, et al. Short term improvement in exercise capacity and symptoms following exercise training in interstitial lung disease. Thorax 2008;63:549-54.

43. Nishiyama $\mathrm{O}$, Kondoh $\mathrm{Y}$, Kimura $\mathrm{T}$, et al. Effects of pulmonary rehabilitation in patients with idiopathic pulmonary fibrosis. Respirology 2008;13:394-9.

44. Huppmann P, Sczepanski B, Boensch M, et al. Effects of inpatient pulmonary rehabilitation in patients with interstitial lung disease. Eur Respir J 2013:42:444-53.

45. Jastrzebski D, Gumola A, Gawlik R, et al. Dyspnea and quality of life in patients with pulmonary fibrosis after six weeks of respiratory rehabilitation. J Physiol Pharmacol 2006;57(Suppl 4):139-48.

46. Holland A, Hill C. Physical training for interstitial lung disease. Cochrane Database Syst Rev 2008;(4):CD006322.
47. Kozu R, Jenkins S, Senjyu H. Effect of disability level on response to pulmonary rehabilitation in patients with idiopathic pulmonary fibrosis. Respirology 2011;16:1196-202.

48. Evans RA, Singh SJ, Collier R, et al. Pulmonary rehabilitation is successful for COPD irrespective of MRC dyspnoea grade. Respir Med 2009;103:1070-5.

49. Kitaguchi Y, Fujimoto K, Hanaoka M, et al. Clinical characteristics of combined pulmonary fibrosis and emphysema. Respirology 2010;15:265-71.

50. Mejía M, Carrillo G, Rojas-Serrano J, et al. Idiopathic pulmonary fibrosis and emphysema: decreased survival associated with severe pulmonary arterial hypertension. Chest 2009;136:10-15.

51. Cottin V, Le Pavec J, Prévot G, et al. GERM"O"P. Pulmonary hypertension in patients with combined pulmonary fibrosis and emphysema syndrome. Eur Respir J 2010;35:105-11.

52. Sugino K, Ishida F, Kikuchi N, et al. Comparison of clinical characteristics and prognostic factors of combined pulmonary fibrosis and emphysema versus idiopathic pulmonary fibrosis alone. Respirology 2014;19:239-45.

53. Desai SA, Channick RN. Exercise in patients with pulmonary arterial hypertension. J Cardiopulm Rehabil Prev 2008;28:12-16. 